\title{
Advances and challenges in the study of the sequelae of child maltreatment
}

\author{
DANTE CICCHETTI \\ Mt. Hope Family Center, University of Rochester
}

Since C. Henry Kempe and his colleagues initially identified the "battered child syndrome" (Kempe, Silverman, Steele, Droegemueller, \& Silver, 1962) in the early 1960s, researchers have directed their energies toward understanding this pervasive and tragic phenomenon. In 1990, the magnitude of child maltreatment led the U.S. Advisory Board on Child Abuse and Neglect to submit a report declaring the existence of a "national emergency" (U.S. Department of Health and Human Services, 1990). In the three decades since the identification of the battered child syndrome, substantial progress has occurred in better understanding the etiology, sequelae, course, and treatment of child maltreatment (Cicchetti \& Toth, 1993). Relatively simplistic main effects models that sought to delimit specific factors that contribute to the occurrence of an act of maltreatment have been replaced by models that strive to account for the complexity and transactions occurring

My work on this special issue was supported in part through funding from the William T. Grant Foundation, the Smith-Richardson Foundation, Inc., the Spencer Foundation, and the Spunk Fund, Inc. I am grateful for the input of my colleagues Kathleen Holt, Jennifer Larter, Fred Rogosch, and Sheree Toth. Finally, as always, I am appreciative of the continued support of the administration of the Monroe County Department of Social Services. I dedicate this Special Issue to the memory of Lisa Flanagan, who, in her all too short life, did much to contribute to the well-being of maltreated children. among the multitude of factors that result in the initiation and maintenance of child maltreatment (Belsky, 1993; Cicchetti \& Lynch, 1993; Cicchetti \& Rizley, 1981). Likewise, operating within an organizational perspective on development, researchers have sought to conduct increasingly sophisticated and methodologically sound investigations of the developmental sequelae of child maltreatment (Cicchetti \& Carlson, 1989; Starr \& Wolfe, 1991).

Despite the progress that has occurred, however, the challenges inherent in conducting work with maltreating families underscore the importance of continuing our research efforts in this area (Cicchetti \& Manly, 1990; Cicchetti \& Toth, 1993; National Research Council, 1993). The contributors to this special issue grapple with a number of issues that have consistently impeded progress in maltreatment research on the consequences of child maltreatment.

Because the identification of child maltreatment cuts across a number of disciplinary perspectives, including arenas involving social services, legal decision-making, child advocacy, and mental health, disagreements in the operationalization of the independent variable have abounded (Aber \& Zigler, 1981; Barnett, Manly, \& Cicchetti, 1993; Giovannoni \& Becerra, 1979; McGee \& Wolfe, 1991). Unfortunately, the lack of consensus regarding the definition of maltreatment employed by various investigators has made comparability across studies 
difficult to achieve. Progress that is being made with regard to increased definitional specificity is apparent in the work of a number of maltreatment researchers represented in this volume.

Another challenge for those invested in conducting research on child maltreatment has involved the confluence of risk factors that often coexist with maltreatment, such as poverty, substance abuse, and domestic violence. While a multiplicity of risk factors are not unique to child maltreatment research (see, e.g., Downey \& Coyne, 1990, and Hammen, 1992, for a similar situation encountered in studies of depression), investigators have not always considered the implications of their decisions regarding sample composition for the interpretation of their findings. Research with maltreating populations that differ on the presence or absence of associated risk factors can only provide a more comprehensive understanding of the occurrence and sequelae of child maltreatment. For example, issues such as whether maltreated children are from the lower socioeconomic strata or whether a range of demographic variables are represented, as well as the utilization of appropriate comparison groups, must be confronted by maltreatment researchers. The contributors to this special issue illustrate some creative approaches to this area.

The conduct of longitudinal research, a rarity with respect to many forms of psychopathological and risk conditions, is an especially elusive goal in maltreatment research. Factors such as the mobility of maltreating families, attrition associated with mandated reporting requirements, and methodological issues related to shifting maltreatment status (e.g., a child designated as comparison at early assessment periods may experience maltreatment over the course of a longitudinal investigation) often conspire against the investigator invested in gaining knowledge in areas involving the long-term outcome of maltreated children or the intergenerational transmission of abuse and neglect. While longitudinal work is being conducted by a number of research groups, a comprehensive body of knowledge has not yet emerged. Thus, both seasoned investigators and those entering into this area of inquiry must be committed to following up their samples if real progress is to be achieved regarding an understanding of the developmental course of child maltreatment. Several studies in this special issue report on longitudinal findings or represent a cohort that is a component of a larger longitudinal investigation. Thus, work on the development of maltreated children over time is beginning to emerge.

An area that has received little attention in recent years, and that is well reflected in this special issue, relates to the elucidation of the mechanisms and processes that eventuate in various outcomes in maltreated children. Rather than focusing solely on group differences on outcome variables that are frequently found between maltreated and nonmaltreated research participants, investigators have begun to examine mechanisms that may mediate the effects of maltreatment. This more sophisticated approach holds great potential for providing an explanation as to the heterogeneous outcomes that have been revealed among maltreated children. By elucidating the underlying processes that may be contributing to a given outcome, a more comprehensive portrayal of functioning becomes possible.

In yet another attempt to understand diverse outcomes and individual differences among maltreated children, investigators have sought to shed light on the occurrence of resilience. Regardless of similar histories of negative caregiving, some maltreated children have been shown to evidence adaptive functioning (Cicchetti, Rogosch, Lynch, \& Holt, in press). The varied outcomes that have been observed among maltreated children despite similar experiences of adversity underscore the importance of conducting work in this area. Several contributions in this issue have begun to examine resilient functioning in maltreated children. Much work remains to be conducted in order to elucidate fully the processes contributing to competent adaptation. The incorporation of 
knowledge derived from investigations into resiliency holds considerable potential for promoting the development of intervention strategies for maltreated populations (Toth \& Cicchetti, 1993).

The authors of the current compilation of articles address many of the issues that must be confronted consistently if the progress that has occurred in three decades of research on child maltreatment is to continue to advance and solidify. While much work still needs to be done, many questions have been answered. Research has consistently

\section{References}

Aber, J. L., \& Zigler, E. (1981). Developmental considerations in defining child maltreatment. In $\mathbf{R}$. Rizley \& D. Cicchetti (Eds.), Developmental perspectives on child maltreatment: New directions for child development (pp. 1-29). San Francisco: Jossey-Bass.

Barnett, D., Manley, J. T., \& Cicchetti, D. (1993). Defining child maltreatment: The interface between policy and research. In D. Cicchetti \& S. L. Toth (Eds.), Child abuse, child development, and social policy (pp. 7-73). Norwood, NJ: Ablex.

Belsky J., (1993). Etiology of child maltreatment: A development-ecological analysis. Psychological Bulletin, 114, 413-433.

Cicchetti, D., \& Carlson, V. (Eds.). (1989). Child maltreatment: Theory and research on the causes and consequences of child abuse and neglect. New York: Cambridge University Press.

Cicchetti, D., \& Lynch, M. (1993). Toward an ecological/transactional model of community violence and child maltreatment: Consequences for children's development. Psychiatry, 56, 96-118.

Cicchetti, D., \& Manly, J. T. (1990). A personal perspective on conducting research on maltreating families: Problems and solutions. In G. $\mathrm{H}$. Brody \& I. E. Sigel (Eds.), Methods of family research: Biographies of research projects: Vol. 2. Clinical populations (pp. 87-133). Hillsdale, NJ: Erlbaum.

Cicchetti, D., \& Rizley, R. (1981). Developmental perspectives on the etiology, intergenerational transmission, and sequelae of child maltreatment. In $\mathbf{R}$. Rizley \& D. Cicchetti (Eds.), Developmental perspectives on child maltreatment: New directions for child development (pp. 31-55). San Francisco: Jossey-Bass.

Cicchetti, D., Rogosch, F. A., Lynch, M., \& Holt, K. D. (1993). Resilience in maltreated children: Pro- documented the effects of maltreatment in undermining the process of development. Moreover, the role of intra- as well as extrafamilial influences on the emergence of maltreatment has been documented consistently. The gains that have occurred and the associated implications for theory, intervention, and policy are due largely to the knowledge base provided by research into the causes, course, and sequelae of child maltreatment. The articles in this issue reflect some of that progress, as well as the challenges that remain before us.

cesses leading to adaptive outcome. Development and Psychopathology, 5, 629-647.

Cicchetti, D., \& Toth, S. L. (Eds.). (1993). Child abuse, child development, and social policy. Norwood, NJ: Ablex.

Downey, G., \& Coyne, J. C. (1990). Children of depressed parents: An integrative review. Psychological Bulletin, 108, 50-76.

Giovannoni, J. M., \& Becerra, R. M. (1979). Defining child abuse. New York: The Free Press.

Hammen, C. (1992). The family-environment context of depression: A perspective on children's risk. In D. Cicchetti \& S. L. Toth (Eds.), Rochester Symposium on Developmental Psychopathology: Vol. IV. Developmental perspectives on depression (pp. 251-281). Rochester, NY: University of Rochester Press.

Kempe, C. H., Silverman, F. N., Steele, B. B., Droegemueller, W., \& Silver, H. K. (1962). The battered child syndrome. Journal of the American Medical Association, 181, 17-24.

McGee, R. A., \& Wolfe, D. A. (1991). Psychological maltreatment: Toward an operational definition. Development and Psychopathology, 3, 119-124.

National Research Council. (1993). Understanding child abuse and neglect. Washington, DC: $\mathrm{Na}$ tional Academy Press.

Starr, R., \& Wolfe, D. A. (Eds.). (1991). The effects of child abuse and neglect: Issues and research. New York: Guilford Press.

Toth, S. L., \& Cicchetti, D. (1993). Child maltreatment: Where do we go from here in our treatment of victims? In D. Cicchetti \& S. L. Toth (Eds.), Child abuse, child development, and social policy (pp. 399-437). Norwood, NJ: Ablex.

U.S. Department of Health and Human Services, (1990). Child abuse and neglect: Critical first steps in response to a national emergency. Washington, DC: U.S. Government Printing Office. 